\title{
Digital Twins for Additive Manufacturing: A State-of-the-Art Review
}

\author{
Li Zhang ${ }^{1,2}{ }^{,}$Xiaoqi Chen ${ }^{2, *}$, Wei Zhou ${ }^{3, *} \mathbb{0}$, Taobo Cheng ${ }^{1}$, Lijia Chen ${ }^{1}{ }^{\mathbb{D}}$, Zhen Guo ${ }^{1}$, \\ Bing Han ${ }^{1}$ and Longxing $\mathrm{Lu}^{1}$ \\ 1 Guangdong Key Laboratory of Modern Control Technology, Guangdong Academy of Sciences, \\ Institute of Intelligent Manufacturing, Guangzhou 510070, China; l.zhang@giim.ac.cn (L.Z.); \\ tb.cheng@giim.ac.cn (T.C.); lj.chen@giim.ac.cn (L.C.); z.guo@giim.ac.cn (Z.G.); b.han@giim.ac.cn (B.H.); \\ lx.luo@giim.ac.cn (L.L.) \\ 2 Faculty of Science Engineering and Technology, Manufacturing Futures Research Institute, \\ Swinburne University of Technology, Hawthorn, VIC 3122, Australia \\ 3 School of Mechanical and Aerospace Engineering, Nanyang Technological University, \\ Singapore 639798, Singapore \\ * Correspondence: xiaoqichen@swin.edu.au (X.C.); wzhou@cantab.net (W.Z.)
}

Received: 30 October 2020; Accepted: 18 November 2020; Published: 24 November 2020

\begin{abstract}
With the development of Industry 4.0, additive manufacturing will be widely used to produce customized components. However, it is rather time-consuming and expensive to produce components with sound structure and good mechanical properties using additive manufacturing by a trial-and-error approach. To obtain optimal process conditions, numerous experiments are needed to optimize the process variables within given machines and processes. Digital twins (DT) are defined as a digital representation of a production system or service or just an active unique product characterized by certain properties or conditions. They are the potential solution to assist in overcoming many issues in additive manufacturing, in order to improve part quality and shorten the time to qualify products. The DT system could be very helpful to understand, analyze and improve the product, service system or production. However, the development of genuine DT is still impeded due to lots of factors, such as the lack of a thorough understanding of the DT concept, framework, and development methods. Moreover, the linkage between existing brownfield systems and their data are under development. This paper aims to summarize the current status and issues in DT for additive manufacturing, in order to provide more references for subsequent research on DT systems.
\end{abstract}

Keywords: additive manufacturing; digital twins; industry 4.0

\section{Introduction}

Nowadays, an increasing number of customized products are needed, which is limited by the capability of the traditional manufacturing methods. Additive manufacturing (AM) is a relatively new way of providing them which is fundamentally different from formative or subtractive manufacturing. The designed structure can be built layer-by-layer directly, instead of casting, forging, or machining [1]. Through this method, nearly all kinds of non-standard structure and irregular workpieces can be made directly without wasting many materials. Thus, additive manufacturing is becoming one of the vital elements of the industrial revolution [2]. However, to produce components with sound structure and good mechanical properties, an optimized combination of appropriate parameters is important. To obtain optimal parameter combination only by trial and error is rather expensive, wastes material, and is time consuming, because numerous experiments are needed to optimize the process variables within given machines and parameter combination [3-6]. In-depth research is underway on 
the technologies of digitization, simulation [7-9], big data, and machine learning [10-12]. And there is a new approach, namely digital twins (DT), to overcome many additive manufacturing issues, such as improving part quality and shortening the time to qualify products. Digital twins are defined as a digital representation of a production system or service or just an active unique product characterized by certain properties or conditions. Through this method, the real physical world could be described by a cyber world. Thus, the physical properties of the components or equipment could be reflected in real-time by the digital model, which is visual and more easily observed. The digital twin system could be helpful to understand, analyze and improve the product, service system or production [13-15].

Thus, the digital twin approach can impact the additive manufacturing process by optimizing the process parameters, detecting, and monitoring the process faults, reducing the computational burden for multi-scale modeling, and dealing with the large volume of in situ sensor data [16].

Digital twins are being explored and gradually used in fields such as maintenance, repair, and overhauls etc., for example, decisionLab Ltd. and Siemens have developed a digital twin, ATOM, which can visualize fleet and maintenance facility operations, capture and predict key performance indicators (KPIs) of the system, and even quickly run a virtual and detailed scenery to help make decision of investment, driven by live data already available within the supply chain. However, the utilization of this technology in AM is still being developed. A lot of work is needed in order to push the digital twin technology forward to serve AM technology.

Here, we searched hundreds of papers in the database of Web of Science, Scopus, Standards, Google Scholar etc. with the key words: Digital Twin (DT), Cyber Physical System (CPS), Additive Manufacturing (AM), Internet of Things (IoT), Big Data, Industry 4.0, Machine Learning etc., and selected the papers that focused on "digital twin for additive manufacturing", or used relevant methods to promote the use of or research into DT in AM, summarized or mentioned the current situation of relevant technologies that could make contributions to the research of DT for AM. By studying and analyzing these papers, we organized this article to provide a reference for the researchers interested in this topic.

\section{State of the Art of Digital Twin for Additive Manufacturing}

The concept of digital twins was firstly proposed by National Aeronautics and Space Administration (NASA) to monitor the behaviors of a satellite. Using this method, the possible changes in the settings could also be simulated. NASA wanted to explore the space using a digital twin replica of the physical system [17]. After that, various studies were undertaken to develop this technology. Till now, it has been constructed and utilized for different manufacturing processes by many industries and government agencies [15].

Recent studies and research indicate that construction of a first-generation digital twin of AM is achievable. However, this technology is still in its infancy, and facing various research challenges. The components required to construct a digital twin of AM hardware, software, and related technologies are still under development and much work is still needed to fulfil its full functions [3].

DebRoy, Yang and their co-workers did lots of the pioneering work in this area $[3,15,18]$. They provided an overarching framework for the implementation, undertook lots of explorations to demonstrate this concept within the AM research community, and provided a perspective of the current status and research needed for the main building blocks of a first-generation digital twin of AM. In their research, they refer to the approach as the digital twin for AM and suggested that a digital twin of 3D printing $[3,18]$ consists of a mechanistic model, a sensing and control model, a statistical model, as well as big data and machine learning, as shown in Figure 1. 


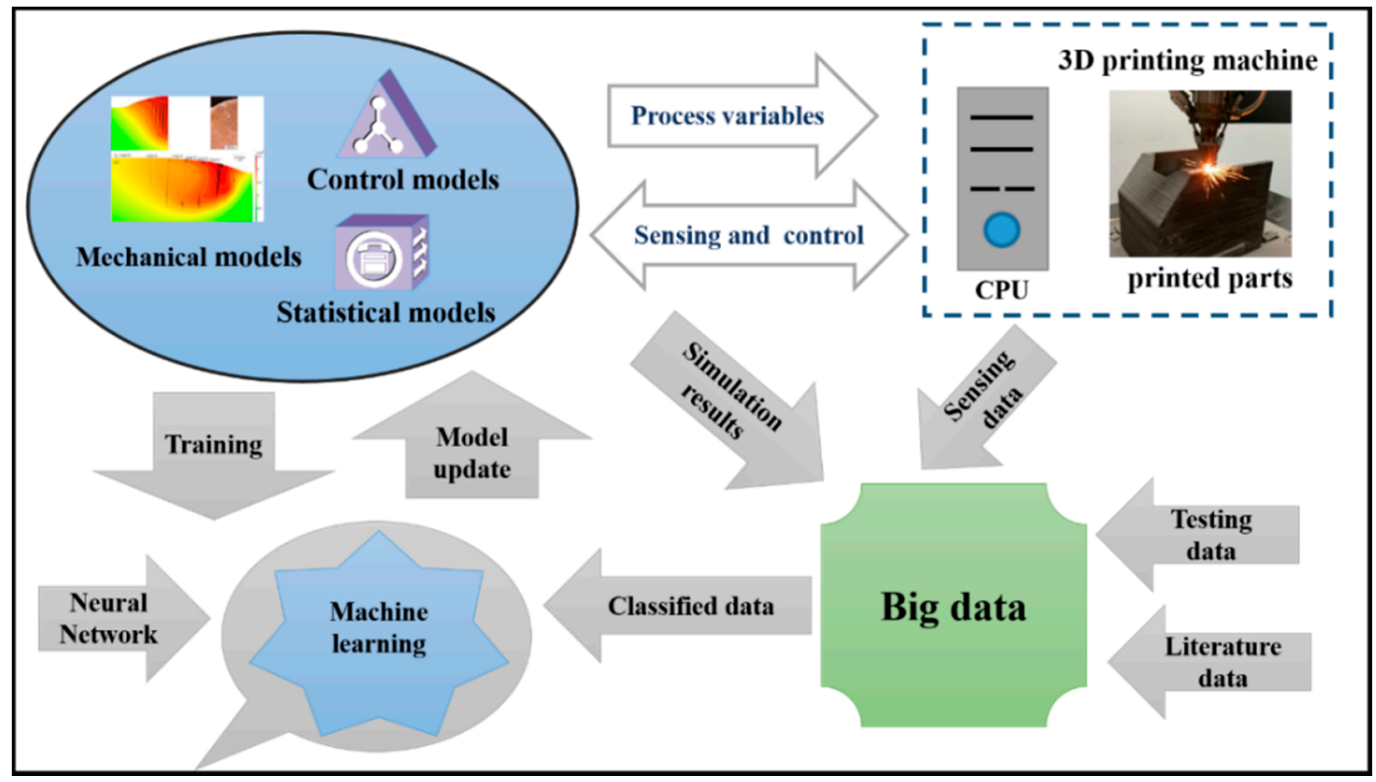

Figure 1. Logical representation of the digital twin for additive manufacturing (AM) $[9,15]$.

Knapp et al. [18] presented a novel framework of a mechanistic model to predict the melt-pool level phenomena. The 3D curved surface deposit geometry for single-pass deposits, transient temperature and velocity distributions, cooling rates, solidification parameters, and secondary dendrite arm spacing and micro-hardness were accurately estimated by the proposed building blocks in a computationally efficient manner. The author called it blocks of a first-generation digital twin of AM.

Yang [19] provided gray-box modeling for a powder bed fusion AM process and demonstrated that it can lower predictive errors, as shown in Figure 2, the basic idea of Yang's team is to make predictions through calculation based on the data obtained, and gray-box modeling is the term used by them, not digital twin.

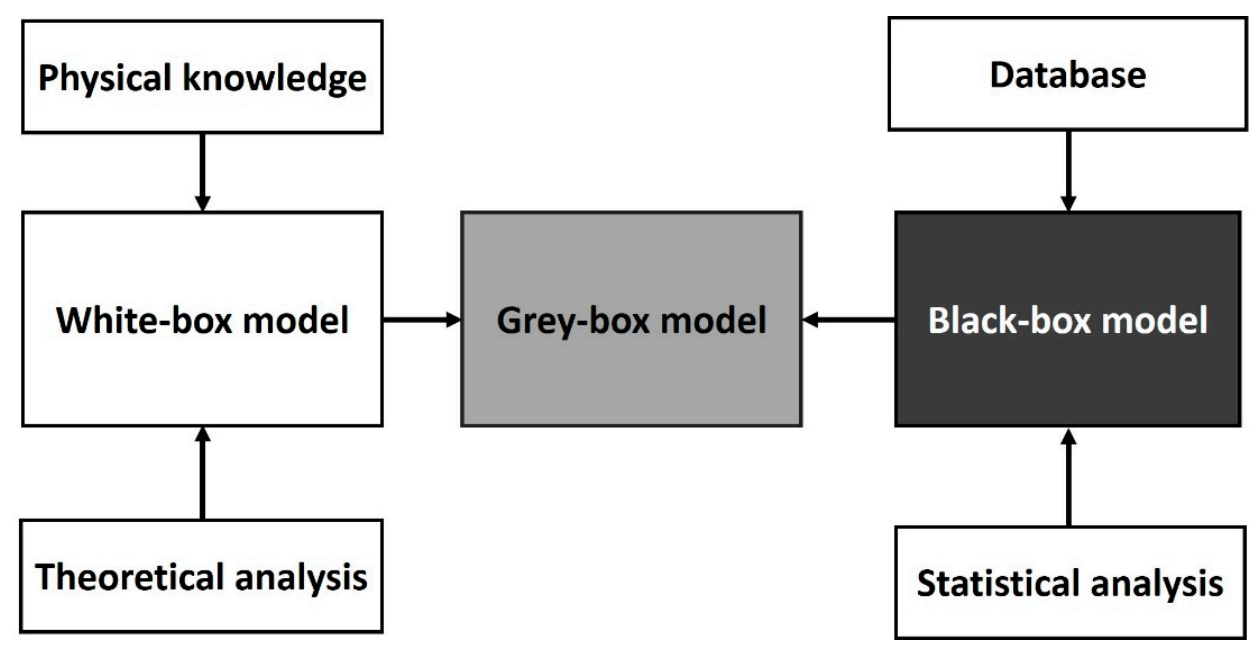

Figure 2. Gray-box model [19].

Gaikwad et al. [16] demonstrated an early foray of the digital twin paradigm for real-time process monitoring and defect prediction. In this research, the combination of physics-driven predictions with in-situ sensor data and machine learning led to higher statistical fidelity in detecting process flaws. The experiments of laser powder bed fusion (LPBF) and directed energy deposition (DED) metal AM processes were both conducted. The results substantiated this conclusion. 
Chhetri et al. [20] did the first work that demonstrated how dynamic data-driven application systems enabled a feature re-ranking method that can help in keeping the digital twin up-to-date, as shown in Figure 3. The key performance indicator is the surface texture of the product and dimension of the object, which is simple and easy to observe. This could be taken as a prediction of the components' "shape", and the target is in a plastic form, which is quite different from the additive manufacturing of metal components.

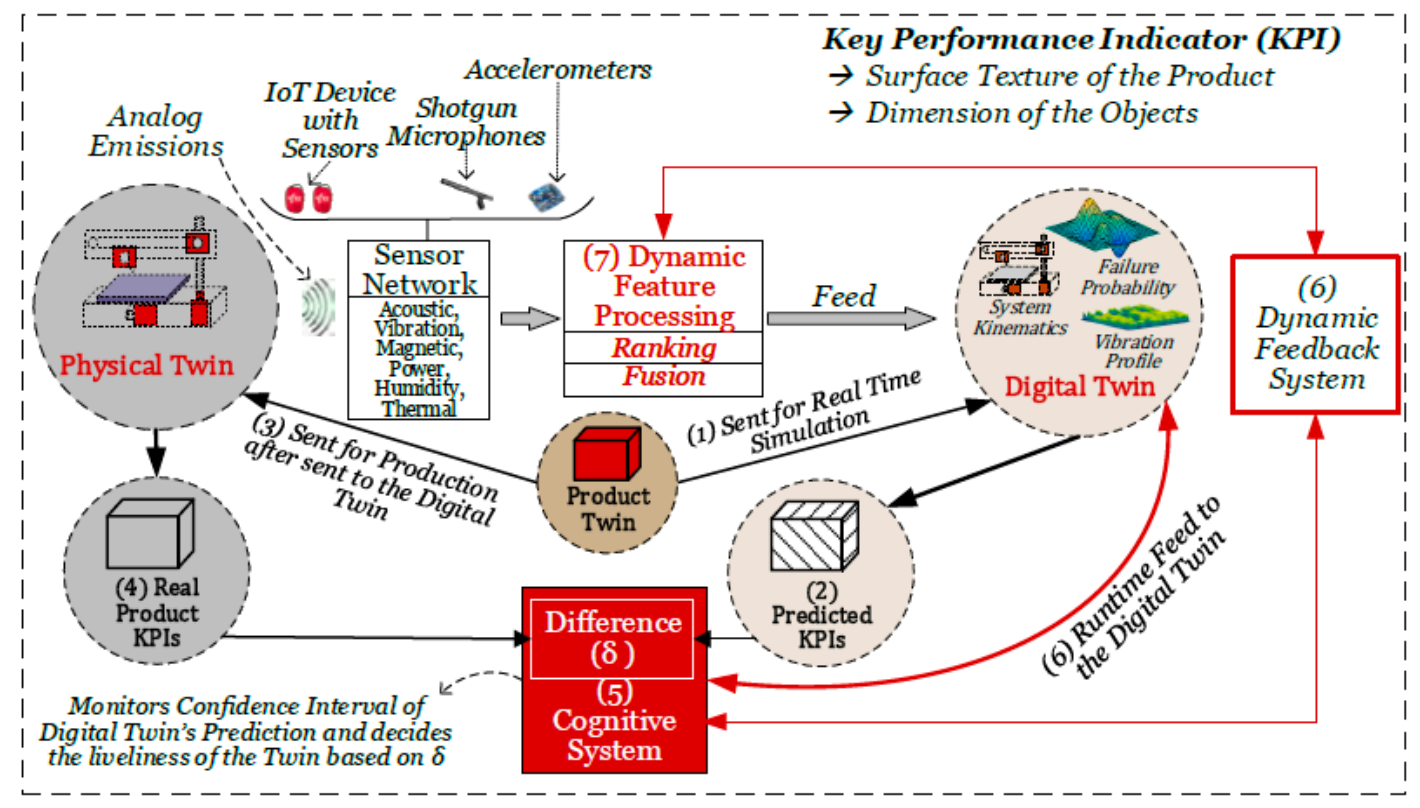

Figure 3. Dynamic data-driven application systems enabled digital twin of additive manufacturing cyber-physical system [20].

All in all, the digital twin in additive manufacturing is a new concept, and the recent research has mainly focused on verifying the concept to predict the temperature distribution and thus to compute the defects that may occur and the relative properties such as the hardness and thermal strain [18]. Basically, the methods are mainly based on the finite element method, finite difference, level set method, volume of fluid method with finite difference method, lattice Boltzmann method and arbitrary Lagrangian-Eulerian, etc. [3]. They are more likely to be called "simulation" instead of "digital twin".

\section{Major Issues and Research Needs}

\subsection{Real Time}

A real-time digital representation of the physical domain in additive manufacturing is needed, to accurately monitor, predict, and control the process. The state of the physical world keeps changing as it continuously interacts with the environment and is influenced by humans. As this may affect the quality of the products, how to predict these interactions and effects of environments is a key factor that needs to be considered [20].

Another main challenge in realizing the real-time digital twin of AM is the computational burden involved in obtaining the heat transfer and thermal distribution, melt-pool solidification, residual stress and distortion, structures and properties of the printed products, and the operation conditions of the machines $[3,16]$. The appropriate sensors could obtain some data such as the temperature distribution.

However, a lot of information needs to be computed and simulated, which is very time consuming based on the currently available computing capabilities. Currently, for the prediction of temperature distribution inside an AM part that is being printed with non-proprietary mesh-based finite element (FE) models will take at least several hours, if not days [16,21-23]. Knapp et al. built a block for a digital twin for laser-directed energy deposition additive manufacturing. Around 3.5 billion linear 
equations are solved for the deposition of one layer, which takes approximately $50 \mathrm{~min}$ in a personal computer with 3.40 Gigahertz i7 processor and 8 Gigabyte RAM (random access memory) [18].

A graph-theoretic computational heat transfer approach was used to predict the temperature distribution parts. It costs $10 \%$ of the time required by $\mathrm{FE}$ analysis and the error was $10 \%$ lower $[16,24]$. This method is operated based on the mathematical premise of a spatial matrix and derivatives represented by the continuous Laplacian operator. This may be a new solution, but further verifications are needed.

\subsection{Database and Models}

The digital twin of AM needs plenty of data to train the model to improve the accuracy of the model. The data could come from experiments, literature, sensors, numerical simulation. However, to collect and classify a sufficiently large volume of useful data is intractable, and usually the concepts of the Internet of Thing (IoT) and cloud computation may be necessary. To date, in actual production, the big data obtained from a product's lifecycle is still isolated, fragmented, and stagnant because the convergence between the product's physical and virtual space is lacking [25], which made it difficult to utilize the data.

There are several types of additive manufacturing processes and many kinds of materials in the forms of wire and powder in different sizes. If the environment during the additive process is considered in modeling, lots of models are needed due to the various combinations, and too much data need to be collected to verify and train the models. Therefore, in order to reduce the computational burden, there is a great need for a temperature-dependent thermophysical properties database for commonly used engineering alloys [3]. Several different types of metal additive manufacturing processes are illustrated in Figure 4, including the directed energy deposition (DED) and powder bed fusion (PBF). They differ in the type of feedstock (powder or wire) and the heat sources (laser, plasma, electronic beam, or gas metal arc) [26]. For each of the commonly used additive manufacturing processes, there should be a standard model, in every different condition (different kinds of materials, protecting gas, machines etc.). The model could be used for the variation of parameters and environments. The users just need to input the data to get the real-time digital twin of the additive manufacturing process. There is still a long way to go to achieve this goal.

\section{Directed energy deposition of powder with laser}

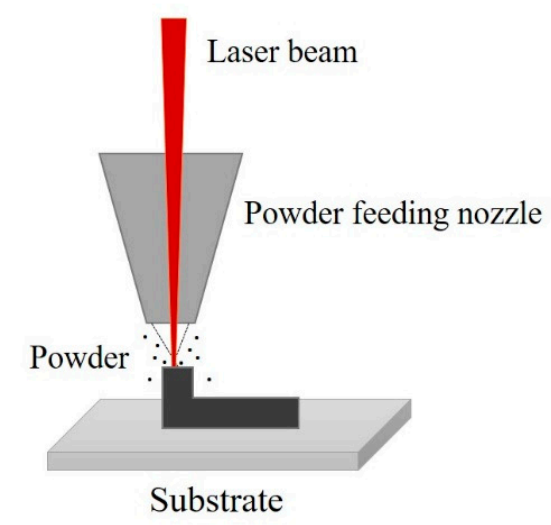

\section{Directed energy deposition with wire}

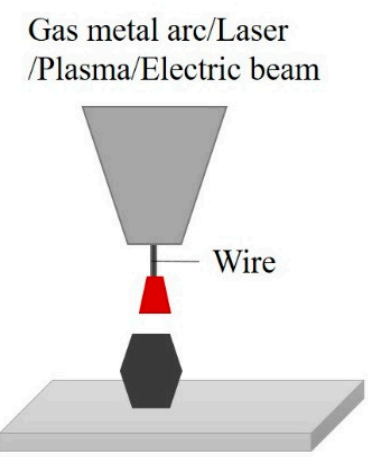

Substrate

\section{Laser powder bed fusion (PBF-L)}

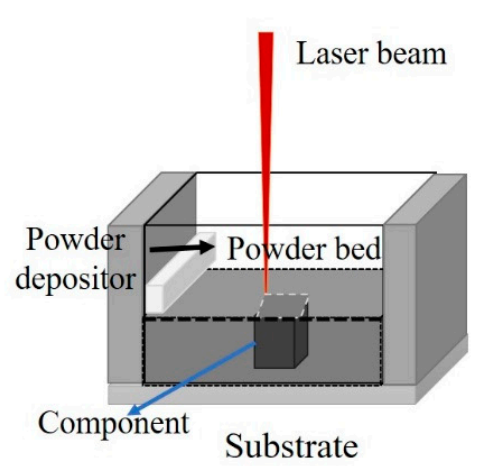

Figure 4. Schematics of main additive manufacturing processes.

\subsection{Prediction of the Additive Manufacturing (AM) Results}

By now, additive manufacturing is still used in a trial-and-error fashion. Lots of experiments should be done and lots of specimens will be destructively tested to check the microstructures and mechanical properties. If a site-specific part is expected, prediction of the AM results is rather important. 
Through the concept of the digital twin, it will be possible to predict the results (geometry, microstructures, and mechanical properties) according to accurate heat transfer models and mechanical models as shown in Figure 5 [15], before actual additive manufacturing, which will provide great help in finding the optimal combination quickly without wasting too much time and material. Currently, the prediction for the AM parts is more likely focused on the distortion and temperature distribution, based on the basic ideas of dividing the part into different unit of grids, and by computing the properties of the grids to obtain the properties of the integral part.

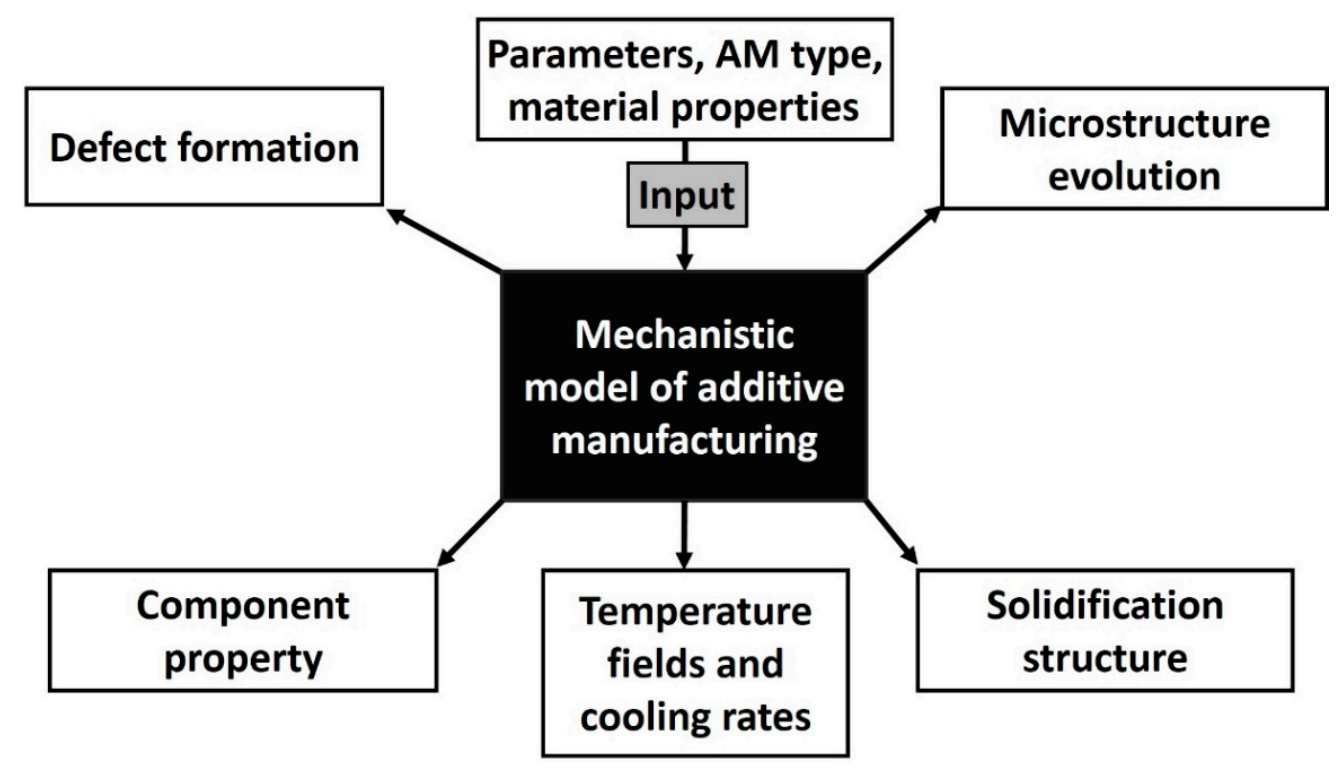

Figure 5. Mechanistic model of 3D printing to predict the results.

Some simulations of the additive manufacturing process are similar to those of welding [4,27], which has been researched in more depth and more well-published knowledge could be leveraged, including prediction of weld metal solidification $[28,29]$ solid-state transformation under single and multi-pass conditions [30,31], as well as static and dynamic mechanical properties [32-36]. Song et al. [9] developed a robust numerical model to simulate convective fluid flow and balancing of surface tension forces at the air-fluid interface. An arbitrary Lagrangian-Eulerian (ALE) moving mesh approach was used to calculate the free surface physical interface. Finally, they successfully predicted the thermal gradient directions and solidified clad dimension. The experimental validation of clad with height and melt-pool depth in various processing parameters were all lower than $10 \%$.

Predicting the thermal history, parts' distortion, microstructure, and mechanical properties are vital. It is also one of the main significant elements of a digital twin for additive manufacturing. Only through prediction of the aforementioned information could it be possible to optimize the parameters and control the process, monitor the conditions, and get the expected results. However, actual tailoring of the final component's properties based on the predictive model is still a long way off [18].

\subsection{Internet of Things}

To adopt a digital twin in additive manufacturing, an effective Internet of Things system is one of the key tools for each part of the system to be linked. A smart connection for the sensors, equipment and system should be effectively achieved. Massive amounts of data in the additive process will be generated and collected to create a digital twin that interacts with the cyber domain by means of the Internet of Things. However, the linkage between existing brownfield systems and their data is under development [7]. There is lots of heterogeneous equipment in an additive manufacturing system. For example, laser-detected energy deposition (DED-L) needs a laser generator to provide power, 
optics to guide and shape the laser beam, a powder feeder or wire feeder to deliver feedstock, a robot or a CNC unit [37] to control and execute the additive manufacturing process, etc. A lot of sensors are needed to monitor the conditions of the process and machines. In order to collect and analyze large amounts of useful data from the equipment and the manufacturing process, how to realize the linkage and smart connection of the hardware and software remains a problem.

As indicated by Tao et al. [38], current solutions have not tended to realize smart interconnections in dealing with heterogeneous equipment, quick configuration and implementation, and online service generation, and the flexibility in connectivity and interactive messaging $[39,40]$ are also very challenging.

In order to realize smart connections for various manufacturing resources, an Industry-Internet-of-Thing Hub (IIhub) based on a Cyber Physical System (CPS) framework was proposed. However, the acquisition of full compatibility for various communication protocols and interfaces is still challenging, and introducing digital twin technology on the shop-floor [38,41] to control the mechanism from cyber space to physical space is also in the workflow of the future.

\subsection{Machine Learning}

To achieve a digital twin for an additive manufacturing system and process, the concept of data driving is rather important, which is based on the technology of machine learning [42-47]. Through learning from data gathered from various resources such as simulation, experiments, literature, machine learning could make reliable predictions $[48,49]$ on microstructure, properties and defects. This technology could extract helpful information and relationships from data instead of from phenomenological guidance or explicit programming; and the solution of complex equations from physical and math problems based on phenomenological understanding could be avoided. Thus, the calculations are rapid [50]. The quality and volume of data will decide the accuracy of the predictions [26]. Ren [10] et al. used a verified thermal field prediction numerical model for Laser Aided Additive Manufacturing (LAAM) to create training data for a physical-based machine-learning algorithm, a combined recurrent neural networks and deep neural networks (RNN-DNN) model was used to make a prediction of the thermal field. The numerical simulation and the RNN-DNN predictions showed agreement of more than $95 \%$.

To obtain a real-time and accurate prediction of the microstructures and mechanical properties, or the occurrence of defects, machine learning is a useful and effective tool, and it is not difficult to build machine-learning programs due to well-tested, user-friendly, and reliable algorithms.

\section{Conclusions and Outlook}

The AM plays an important role in advanced manufacturing in the age of Industry 4.0. Currently, it is still carried out in a trial-and-error fashion, where many builds are done before the optimal printing conditions are found, with a corresponding waste of material, machine operator time, and printer depreciation. The digital twin is a new way to overcome many additive manufacturing issues, such as process simulation, process monitoring and control. It can help to understand in depth the roles of various manufacturing parameters, and the sensitivity of these parameters to the product quality. Furthermore, it can provide feedback information for active control of the manufacturing process.

It is not difficult to imagine that, the digital twin technology could make the whole additive manufacturing visualized, and the KPIs of the components could be quickly and precisely predicted with the input parameters, and that it will tell you what are the bottlenecks and risks for the system to manufacture the part. With the IoT, live data driving could optimize the process as long as you tell the system what you want.

The first generation of digital twins for additive manufacturing is still developing. This technology is able to push additive manufacturing forward. However, lots of work needs to be carried out on developing models, databases, machine learning, integration of the equipment, and algorithms to deal with data, and predict the results. 
Author Contributions: Conceptualization, T.C. and X.C.; methodology, W.Z.; validation, L.C.; investigation, Z.G.; and L.L.; resources, B.H.; writing-Original draft preparation, L.Z.; writing-Review and editing, L.Z. and W.Z.; supervision, X.C. and W.Z.; All authors have read and agreed to the published version of the manuscript.

Funding: This article was supported by the Academy of Sciences Project of Guangdong Province (2016GDASRC-0105), 2017GDASCX-0115 and 2018GDASCX-0115.

Conflicts of Interest: The authors declare no conflict of interest.

\section{References}

1. Tofail, S.A.M.; Koumoulos, E.P.; Bandyopadhyay, A.; Bose, S.; O’Donoghue, L.; Charitidis, C. Additive manufacturing: Scientific and technological challenges, market uptake and opportunities. Mater. Today 2018, 21, 22-37. [CrossRef]

2. Dilberoglu, U.M.; Gharehpapagh, B.; Yaman, U.; Dolen, M. The Role of Additive Manufacturing in the Era of Industry 4.0. Proc. Manuf. 2017, 11, 545-554. [CrossRef]

3. DebRoy, T.; Zhang, W.; Turner, J.; Babu, S.S. Building digital twins of 3D printing machines. Scr. Mater. 2017, 135, 119-124. [CrossRef]

4. Manvatkar, V.; De, A.; DebRoy, T. Heat transfer and material flow during laser assisted multi-layer additive manufacturing. J. Appl. Phys. 2014, 116, 124905. [CrossRef]

5. Manvatkar, V.; De, A.; DebRoy, T. Spatial variation of melt pool geometry, peak temperature and solidification parameters during laser assisted additive manufacturing process. Mater. Sci. Technol. 2015, 31, 924-930. [CrossRef]

6. Raghavan, A.; Wei, H.L.; Palmer, T.A.; DebRoy, T. Heat transfer and fluid flow in additive manufacturing. J. Laser Appl. 2013, 25, 52006. [CrossRef]

7. Song, J.; Chew, Y.; Jiao, L.; Yao, X.; Moon, S.K.; Bi, G. Numerical study of temperature and cooling rate in selective laser melting with functionally graded support structures. Addit. Manuf. 2018, 24, 543-551. [CrossRef]

8. Loh, L.-E.; Song, J.; Guo, F.; Bi, G. Analytical Solution of Temperature Distribution in a Nonuniform Medium Due to a Moving Laser Beam and a Double Beam Scanning Strategy in the Selective Laser Melting Process. J. Heat Transf. 2018, 140. [CrossRef]

9. Song, J.; Chew, Y.; Bi, G.; Yao, X.; Zhang, B.; Bai, J.; Moon, S.K. Numerical and experimental study of laser aided additive manufacturing for melt-pool profile and grain orientation analysis. Mater. Des. 2018, 137, 286-297. [CrossRef]

10. Ren, K.; Chew, Y.; Zhang, Y.F.; Fuh, J.Y.H.; Bi, G.J. Thermal field prediction for laser scanning paths in laser aided additive manufacturing by physics-based machine learning. Comput. Methods Appl. Mech. Eng. 2020, 362, 112734. [CrossRef]

11. Ren, K.; Chew, Y.; Zhang, Y.F.; Bi, G.J.; Fuh, J.Y.H. Thermal analyses for optimal scanning pattern evaluation in laser aided additive manufacturing. J. Mater. Proc. Technol. 2019, 271, 178-188. [CrossRef]

12. Ren, K.; Chew, Y.; Fuh, J.Y.H.; Zhang, Y.F.; Bi, G.J. Thermo-mechanical analyses for optimized path planning in laser aided additive manufacturing processes. Mater. Des. 2019, 162, 80-93. [CrossRef]

13. Stark, R.; Fresemann, C.; Lindow, K. Development and operation of Digital Twins for technical systems and services. CIRP Ann. 2019, 68, 129-132. [CrossRef]

14. Schleich, B.; Anwer, N.; Mathieu, L.; Wartzack, S. Shaping the digital twin for design and production engineering. CIRP Ann. 2017, 66, 141-144. [CrossRef]

15. Mukherjee, T.; DebRoy, T. A digital twin for rapid qualification of 3D printed metallic components. Appl. Mater. Today 2019, 14, 59-65. [CrossRef]

16. Gaikwad, A.; Yavari, R.; Montazeri, M.; Cole, K.; Bian, L.; Rao, P. Toward the digital twin of additive manufacturing: Integrating thermal simulations, sensing, and analytics to detect process faults. IISE Trans. 2020, 52, 1204-1217. [CrossRef]

17. Tuegel, E.J.; Ingraffea, A.R.; Eason, T.G.; Spottswood, S.M. Reengineering Aircraft Structural Life Prediction Using a Digital Twin. Int. J. Aerosp. Eng. 2011, 2011, 1-14. [CrossRef]

18. Knapp, G.L.; Mukherjee, T.; Zuback, J.S.; Wei, H.L.; Palmer, T.A.; De, A.; DebRoy, T. Building blocks for a digital twin of additive manufacturing. Acta Mater. 2017, 135, 390-399. [CrossRef] 
19. Yang, Z. Model-Based Predictive Analytics for Additive and Smart Manufacturing. Ph.D. Thesis, University of Massachusetts, Amherst, MA, USA, 2018.

20. Chhetri, S.R.; Faezi, S.; al Faruque, M.A. Digital Twin of Manufacturing Systems: Technical Report on Digital Twin Project; Center for Embedded and Cyber-physical Systems (CECS), University of California: Irvine, CA, USA, November 2017.

21. Luo, Z.; Zhao, Y. A survey of finite element analysis of temperature and thermal stress fields in powder bed fusion Additive Manufacturing. Addit. Manuf. 2018, 21, 318-332. [CrossRef]

22. Francois, M.M.; Sun, A.; King, W.E.; Henson, N.J.; Tourret, D.; Bronkhorst, C.A.; Carlson, N.N.; Newman, C.K.; Haut, T.; Bakosi, J.; et al. Modeling of additive manufacturing processes for metals: Challenges and opportunities. Curr. Opin. Solid State Mater. Sci. 2017, 21, 198-206. [CrossRef]

23. Bandyopadhyay, A.; Traxel, K.D. Invited Review Article: Metal-additive manufacturing-Modeling strategies for application-optimized designs. Addit. Manuf. 2018, 22, 758-774. [CrossRef]

24. Yavari, M.R.; Cole, K.D.; Rao, P. Thermal Modeling in Metal Additive Manufacturing Using Graph Theory. J. Manuf. Sci. Eng. 2019, 141. [CrossRef]

25. Tao, F.; Cheng, J.; Qi, Q.; Zhang, M.; Zhang, H.; Sui, F. Digital twin-driven product design, manufacturing and service with big data. Int. J. Adv. Manuf. Technol. 2018, 94, 3563-3576. [CrossRef]

26. DebRoy, T.; Mukherjee, T.; Wei, H.L.; Elmer, J.W.; Milewski, J.O. Metallurgy, mechanistic models and machine learning in metal printing. Nat. Rev. Mater. 2020, 1-21. [CrossRef]

27. Sames, W.J.; List, F.A.; Pannala, S.; Dehoff, R.R.; Babu, S.S. The metallurgy and processing science of metal additive manufacturing. Int. Mater. Rev. 2016, 61, 315-360. [CrossRef]

28. Dye, D.; Hunziker, O.; Reed, R.C. Numerical analysis of the weldability of superalloys. Acta Mater. 2001, 49, 683-697. [CrossRef]

29. David, S.A.; Vitek, J.M. Correlation between solidification parameters and weld microstructures. Int. Mater. Rev. 1989, 34, 213-245. [CrossRef]

30. Kirkaldy, J.S. Diffusion-controlled phase transformations in steels-Theory and applications. Scand. J. Metall. 1991, 20, 50-61.

31. Reed, R.C.; Bhadeshia, H.K.D.H. A simple model for multipass steel welds. Acta Metall. Mater. 1994, 42, 3663-3678. [CrossRef]

32. Yang, Y.P.; Babu, S.S.; Orth, F.; Peterson, W. Integrated computational model to predict mechanical behaviour of spot weld. Sci. Technol. Weld. Join. 2008, 13, 232-239. [CrossRef]

33. Watt, D.F.; Coon, L.; Bibby, M.; Goldak, J.; Henwood, C. An algorithm for modelling microstructural development in weld heat-affected zones (part a) reaction kinetics. Acta Metall. 1988, 36, 3029-3035. [CrossRef]

34. Kang, H.; Dong, P.; Hong, J. Fatigue analysis of spot welds using a mesh-insensitive structural stress approach. Int. J. Fatigue 2007, 29, 1546-1553. [CrossRef]

35. Ion, J.C.; Easterling, K.E.; Ashby, M.F. A second report on diagrams of microstructure and hardness for heat-affected zones in welds. Acta Metall. 1984, 32, 1949-1962. [CrossRef]

36. Bhadeshia, H.K.D.H. Neural Networks in Materials Science. ISIJ Int. 1999, 39, 966-979. [CrossRef]

37. Saboori, A.; Aversa, A.; Bosio, F.; Bassini, E.; Librera, E.; de Chirico, M.; Biamino, S.; Ugues, D.; Fino, P.; Lombardi, M. An investigation on the effect of powder recycling on the microstructure and mechanical properties of AISI 316L produced by Directed Energy Deposition. Mater. Sci. Eng. A 2019, 766, 138360. [CrossRef]

38. Tao, F.; Cheng, J.; Qi, Q. IIHub: An Industrial Internet-of-Things Hub Toward Smart Manufacturing Based on Cyber-Physical System. IEEE Trans. Ind. Inf. 2018, 14, 2271-2280. [CrossRef]

39. Schlegel, T.; Thiel, S.; Foursa, M.; Meo, F.; Larranaga, J.; Ibarbia, J.A.; Haidegger, G.; Mezgar, I.; Paniti, I.; Praturlon, A.H.; et al. Smart connected and interactive production control in a distributed environment. IJCAET 2011, 3, 322. [CrossRef]

40. Kang, H.S.; Lee, J.Y.; Choi, S.; Kim, H.; Park, J.H.; Son, J.Y.; Kim, B.H.; Noh, S.D. Smart manufacturing: Past research, present findings, and future directions. Int. J. Precis. Eng. Manuf. Green Technol. 2016, 3, 111-128. [CrossRef]

41. Tao, F.; Zhang, M. Digital Twin Shop-Floor: A New Shop-Floor Paradigm Towards Smart Manufacturing. IEEE Access 2017, 5, 20418-20427. [CrossRef] 
42. Zhang, B.; Jaiswal, P.; Rai, R.; Guerrier, P.; Baggs, G. Convolutional neural network-based inspection of metal additive manufacturing parts. RPJ 2019, 25, 530-540. [CrossRef]

43. Aoyagi, K.; Wang, H.; Sudo,H.; Chiba, A. Simple method to construct process maps for additive manufacturing using a support vector machine. Addit. Manuf. 2019, 27, 353-362. [CrossRef]

44. Wang, Y.; Blache, R.; Zheng, P.; Xu, X. A Knowledge Management System to Support Design for Additive Manufacturing Using Bayesian Networks. J. Mech. Des. 2018, 140. [CrossRef]

45. Wu, D.; Wei, Y.; Terpenny, J. Predictive modelling of surface roughness in fused deposition modelling using data fusion. Int. J. Prod. Res. 2019, 57, 3992-4006. [CrossRef]

46. Zhao, Z.; Guo, Y.; Bai, L.; Wang, K.; Han, J. Quality monitoring in wire-arc additive manufacturing based on cooperative awareness of spectrum and vision. Optik 2019, 181, 351-360. [CrossRef]

47. Du, Y.; Mukherjee, T.; DebRoy, T. Conditions for void formation in friction stir welding from machine learning. NPJ Comput. Mater. 2019, 5. [CrossRef]

48. Mitchell, T.M. Machine Learning; McGraw-Hill: New York, NY, USA, 1997.

49. LeCun, Y.; Bengio, Y.; Hinton, G. Deep learning. Nature 2015, 521, 436-444. [CrossRef]

50. Jordan, M.I.; Mitchell, T.M. Machine learning: Trends, perspectives, and prospects. Science 2015, 349, $255-260$. [CrossRef]

Publisher's Note: MDPI stays neutral with regard to jurisdictional claims in published maps and institutional affiliations.

(C) 2020 by the authors. Licensee MDPI, Basel, Switzerland. This article is an open access article distributed under the terms and conditions of the Creative Commons Attribution (CC BY) license (http://creativecommons.org/licenses/by/4.0/). 